\title{
Teaching Leadership Better: A Framework for Developing Contextually-Intelligent Leadership
}

\author{
Josephine Chinying Lang \\ Nanyang Business School, Nanyang Technological University, Singapore \\ Email: acylang@ntu.edu.sg
}

How to cite this paper: Lang, J. C. (2019). Teaching Leadership Better: A Framework for Developing Contextually-Intelligent Leadership. Creative Education, 10, 443-463. https://doi.org/10.4236/ce.2019.102032

Received: January 15, 2019

Accepted: February 22, 2019

Published: February 25, 2019

Copyright ( 2019 by author(s) and Scientific Research Publishing Inc. This work is licensed under the Creative Commons Attribution International License (CC BY 4.0).

http://creativecommons.org/licenses/by/4.0/

\begin{abstract}
This paper discusses the importance of context, which is that which makes content relevant and meaningful. It highlights what context ought to mean for organizational leaders, given today's business environment of crunching change. Based on published research about context, this paper develops a model of contextual intelligence, upon which better ways of teaching leadership may be cultivated. This model encompasses four concerns, namely: contextual sense-making; situation awareness and situation judgment; contextual adaptation; and, response judgment. Next, the paper focuses on the requisite complexity that leaders should acquire if they are to operationalize such a model. That requisite complexity comprises four components, namely: general cognitive complexity; social complexity; affective complexity; and, self-complexity. The paper finally delineates a pedagogical framework to develop leadership training programs that can better foster the requisite complexity in individuals to become contextually-intelligent leaders.
\end{abstract}

\section{Keywords}

Contextual Intelligence, Leadership, Requisite Complexity, Active Learning, Social Complexity, Self-Complexity, Affective Complexity, Situation Awareness, Situation Judgment, Sense-Making, Contextual Adaptation, Assessment Rubrics

\section{Introduction}

It is a trite fact to note that today's business environment is shot through with dynamic and challenging change. This has arisen from, among other factors, a conjuncture of several technological forces, namely, digitization, artificial intelligence, big data analytics, machine learning, and cloud computing. This conjuncture has rendered obsolete what used to be fundamental business assumptions and transformed the business landscape into a global, network-based, and 
knowledge-intensive one. According to Tetenbaum and Laurence (2011: p. 41), this sea change in the business environment may be likened to a "transition from a Newtonian paradigm of control and equilibrium to one of chaos and disequilibrium".

Business leadership has not met this challenge. According to a World Economic Forum report (2015) based on its Survey on the Global Agenda, 86\% of 1767 respondents identified leadership crises as the third most significant challenge facing the world today. A Center for Creative Leadership survey concerning this leadership gap, that involved 2239 leaders from twenty four organizations in three countries, found that crucial leadership skills were not meeting adequately the current challenges organizations were facing and their future requirements (Leslie, 2015). Another study by APQC, a member-based nonprofit, to unearth the reasons behind this leadership crisis found a lack of mastery of the required competencies or lack of focus on the necessary skills. Ciampa (2005) opined that new CEOs failed to perform in their first 18 months because of their inability to go beyond their own competence, or knowledge, or experience.

Despite a plethora of leadership theories and frameworks, many of these are too simplistic and insufficiently rigorous to address the volatility, uncertainty, complexity, and ambiguity, or VUCA, environment. Tetenbaum \& Laurence (2011) noted that the trait theory, skills theory, and the style theory (Zaccaro, Kemp, \& Bader, 2004; Mumford, Zaccaro, Connelly, \& Marks, 2000; Blake \& Mouton, 1985) focused excessively on the individual leader. Meanwhile, situational leadership and leader-member exchange theories (Blanchard, Zigarmi, \& Nelson, 1993; Graen \& Uhl-Bien, 1995), overly stressed the dyadic relationships between leaders and followers. Although contingency theory (Fiedler, 1964) did factor in context, its recommendation of changing the setting in case of mismatch may be infeasible in today's business environment. Or, consider transformational leadership theory (Bass \& Avolio, 1990), which was found wanting for its lack of focus on context, so it too would be ineffective in equipping leaders with the requisite competencies to manage in the current VUCA environment.

In a knowledge economy with crunching change, it is imperative then that leadership must be contextualized to fit current realities. This paper explores a sorely neglected aspect of leadership development programs based on the rather intuitive idea that learning involves not just grasping new concepts and acquiring explicit knowledge content but also recognizing in what contexts these may be appropriately applied. The bulk of this paper will unavoidably be devoted to explicating context, contextual intelligence, and the requisite complexity to acquire that intelligence. Only afterwards can the theoretical underpinnings of a pedagogical framework to operationalize these concepts make sense.

In Part 2, this paper canvasses how inadequate leadership development programs are, being currently based largely on a-contextual, linear thinking that 
does not fit today's VUCA environments of crunching change. Next, in Part 3, the notion of context is reviewed while the idea of and theoretical foundations for a model of contextual intelligence are sketched out in Part 4. But leaders must have the requisite complexity if they are to develop their contextual intelligence. Thus, in Part 5, a framework centered on the requisite complexity to develop contextually intelligence in leaders is described. Clearly, how to foster this requisite complexity will be dispositive. Thus, Part 6 offers the conceptual underpinnings of a pedagogical framework for active learning that can inculcate that requisite complexity to foster contextual intelligence in leadership training. The paper then concludes.

\section{The Inadequacy of Current Leadership Training Paradigms}

Leaders, like everyone else, are always to be found within specific social contexts, which is why what their behaviors mean will necessarily be socially constructed (Gronn, 2002). This is plain to see if we consider just how the relevant contexts in terms of causations and contingencies that military leaders might have to deal depend on whether lives are at risk or not. However, such considerations are obviously not routine concerns for leaders in civilian life, whether for-profit or not-for-profit sectors (Hannah, Campbell, \& Matthews, 2010). Thus, a leadership course for participants from the military world ought to significantly differ from that for business executives. It would be less than ideal to teach both sets of participants the same sets of leadership theories, when military and civilian operational contexts obviously differ. Yet they might well be run with little difference.

Still, much of leadership training comprises the imparting of theoretical knowledge about leadership with little regard to context (Boal, 2000). Anecdotally speaking, most run-of-the-mill leadership courses use usually a combination of stand-and-deliver lectures, and case studies, that lead to the passive learning of explicit knowledge (Geist \& Myers, 2007), without any emphasis on context. The content typically focuses on leadership theories, behaviors, and assessments. On leadership theories, for example, the instructor may focus on leaders' psychological make-up; situational leadership theories; transactional versus transformational leadership styles, etc. On leadership behaviors, the teacher may look at visioning; influencing others; goal setting; managing change; managing teams; leader-follower relations, and leadership styles, etc. On assessing leadership, the course teacher may look at personality assessments, 360-degree feedback, and competencies assessment, etc. In all this, context might be mentioned in a cursory manner. How contextual elements might impact leadership would likely be given short shrift.

While leaders must obviously adapt to changes in contexts (Hooijberg, Hunt, \& Dodge, 1997), leadership theories rarely emphasize contextualization. Howev-

er, the rise of big data analytics, artificial intelligence (AI) machine learning $(\mathrm{ML})$, and blockchain technologies is going to revolutionize practically every fa- 
cet of the business world. The convergence of these technologies will transform education, manufacturing, financial services, and so on, rendering some business processes obsolescent more quickly while creating new business opportunities for others. If so, prevailing leadership theories fit present day VUCA environments poorly.

This prevalent inattentiveness to context may be attributed to the fact that context is neither visible nor tangible. First, the relevant context may well appear to be constant or unchanging, especially if one focuses on the phenomenon of interest over too brief a time frame (Johns, 2006). In addition, to chase down the facts and figures about a particular context entails effort and expends energy, whereas the importance of context is not immediately obvious, given the widespread assumption that theories are generally universal in their applicability. But if leadership theories may not be applied universally across different contexts-compare military versus civilian contexts, say-how then is one to decide which theory to apply to what context?

Much of leadership training tends to be based on linear thinking just because most people tend to think in a linear fashion, something well attested to by research in cognitive psychology (Plowman \& Dochon, 2008). While linear thinking may suffice when dealing with known types of problems that have known solutions, it may likely lead to a narrow managerial focus on preserving stability, where change is regarded as episodic and inconvenient. This kind of thinking makes for poor thinkers, who go on to make poor quality decisions and may be quite unprepared to innovate within VUCA contexts (Weberg, 2012).

Linear thinking is likely to be a poor fit for complex contexts in which many managerial problems find themselves and may lead to the generation of simplistic explanations for complex phenomena, thus limiting managerial ability to understand and deal with them effectively. Such an orientation that many a manager may have could lead to reactive rather than proactive behaviors. Since complex problems in VUCA business contexts are non-linear, it makes sense that they ought not to be approached linearly (Plowman \& Duchon, 2008).

Instead, these must be approached contextually. This would require organizational leaders to recognize that contexts vary by levels, adapt their thinking adroitly in response to changes in those contexts, and then respond appropriately (Uhl-Bien et al., 2008; Hannah, Balthazard, Waldman, Jennings, \& Thatcher, 2013). Such leaders have to descry contexts accurately, think nonlinearly through novel situations, understand the challenges they are facing, communicate clearly that understanding to critical stakeholders, and, finally, make the required course corrections for the organizations they lead. In short, context and contextualization matter a great deal for today's leaders, to which we now turn.

\section{The Importance of Context for Leadership}

To contextualize something is simply to place it within a context, or that situation within which the phenomenon of interest is to be found and can help ex- 
plain it. According to Rousseau and Fried (2001: p. 1), such an effort "entails linking observations to a set of relevant facts, events, or points of view that make possible research and theory that form part of a larger whole". In this way, contextualization helps leaders understand the challenges they may be facing for context shapes meanings, e.g. the Arab Spring in 2010 may help to explain the financial performance of many airlines and oil companies at the time.

In the literature, context may be viewed as external stimuli, surroundings, or situations that impute meanings to and impact upon the issue of interest. First, contexts vary at different levels of analysis: "context encompasses stimuli and phenomena that surround and thus exist in the environment external to the individual, most often at a different level of analysis" (Mowday \& Sutton, 1993: p. 198). Concurring, Cappelli and Sherer (1991: p. 56) have noted that "the surroundings associated with phenomena which help to illuminate [those] phenomena [are] typically factors associated with units of analysis ..."

Secondly, contexts tend to be unique: "context consists of all the external, internal, interpersonal, and intrapersonal factors that contribute to the uniqueness of each situation and circumstance" (Kutz, 2008: p. 20). Thirdly, contexts speak to constraints but opportunities as well for, as Johns (2006: p. 386) has noted, context is the set of "situational opportunities and constraints that affect the occurrence and meaning of organizational behavior as well as functional relationships between variables".

The upshot is that all contexts are not equal. Thus, all contexts do not matter to the same extent. Depending on the phenomenon of interest, contexts may differ by levels of analysis. Within an organization, contexts may differ at individual, group, and organization levels of analysis. But external to an organization, contexts may differ at five levels of analysis that Castrogiovanni (1991) proposed, viz., resource pool, sub-environment, task environment, aggregate environment, and macro-environment (Figure 1).

At the lowest level of analysis, i.e. that of the resource pool in the external environment, the major contextual concerns are the availability and acquisition of specific resources. Next comes the sub-environment level, the context that is most relevant for understanding the decisions and actions of a subunit within an organization. An example of this would be the detergent subsector of the domestic market for a particular sales unit of a firm marketing consumer products.

Then, there is the task environment, which consists of multiple sub-environments, such as customers, suppliers, bankers, competitors, etc. At this contextual level, the main concern is how an organization differentiates itself from others. Next is the aggregate environment, which comprises associational groups, including industry associations, sectoral interest groups, and so on. At this contextual level, the main considerations are the interests, concerns, perceptions, and behaviors of these groups. Finally, the highest contextual level is the macro-environment, comprising the prevailing economic, political, social, technological, and regulatory trends.

Contexts at different levels differ. For example, a tariff war between the US 
Contextual Influences

(a) Opportunity and constrain

(b) Distal or proximate stimuli

(c) Similar or dissimilar

\begin{tabular}{|l|l|}
\hline Contextual Levels & Contextual Factors \\
\hline \multicolumn{2}{|l|}{ Intra-organizational } \\
\hline Organization & Top management, organization culture \\
\hline Group & Project team, work group \\
\hline Individual & Manager, supervisor, peer \\
\hline Extra-organizational \\
\hline Macro environment & Politic, economic, social, technology, etc. \\
\hline $\begin{array}{l}\text { Aggregate } \\
\text { environment }\end{array}$ & Associations, interest groups, etc. \\
\hline Task environment & Customer, suppliers, etc. \\
\hline Sub-environment & $\begin{array}{l}\text { Pertinent environmental factors for } \\
\text { subunits }\end{array}$ \\
\hline Resource Pool & $\begin{array}{l}\text { Resource munificence, resource } \\
\text { acquisition }\end{array}$ \\
\hline
\end{tabular}

Figure 1. Contextual influences.
Channels of Contextual

Influences

(a) Powerful Individuals

(b) Powerful Groups -Aggregate member thoughts, feelings, and behaviours
Phenomenon of interest

and China in the macro environment may dampen the future prospects of soy farms (aggregate environment), create negative sentiment in the stock market (an option trader's task environment), and, possibly affect a CEO's investment decisions (resource pool). There are also other miscellaneous contextual considerations. A particular context may appear to be a combination of stimuli, e.g. the financial sector is facing challenges thrown at it by a combination of AI, ML, and big data. Sometimes just a specific event may well be the most important context. For example, Congress passed a 2005 law called the Energy Policy Act, which laid down the Renewable Fuel Standard (RFS) mandating that all transportation fuel sold in the United States must have a minimum volume of renewable fuel. The RFS inflated global food prices, which worsened rural poverty in India (Chakravorty, Hubert, \& Marchand, 2018).

Now that we have seen that context is not homogenous but rather variegated, the question that needs to be asked is how the influence of the various levels of context may be activated. Mowday and Sutton (1993) suggested that contextual considerations are activated along three axes and therefore can be analyzed accordingly. These axes are: whether there are opportunities for, or constraints on behavior; whether the relevant stimuli are proximate or distal; and, whether there is similarity or dissimilarity.

First, as to whether certain situations are perceived as presenting opportunities to be exploited or, contrariwise, as constraints upon what one may do may depend upon prevailing social expectations, norms, and mores. Secondly, stimuli that are perceived to be more proximate, either spatially or temporally, tend to 
matter more compared to those that are perceived to be more distal, whether spatially or temporally. That is, the salience of a situational feature matters, e.g. an impending hurricane in the path of a plane's flight is salient, or heavy snow accumulation on the runway matters a lot to a pilot trying to land his plane. Mixed into this might be what is called a situation's intensity or strength (Johns, 2006). A strong situation is that characterized by deeply ingrained norms and highly rigid expectations, where there are fewer degrees of freedom to act, e.g. religious injunctions, say. By contrast, a weak situation is one with fewer constraints upon action, like the office Christmas party. Finally, in contexts of similarity or homogeneity in terms of demographics, personality, values, and interests, there may be more trust and closer communication, in contrast to contexts with dissimilarity or heterogeneity.

While contextual considerations are activated along these three axes, the question is how the influence of these contextual considerations get channeled? The answer is that they get channeled through powerful individuals and powerful groups (Mowday \& Sutton, 1993). The impact of powerful individuals such as experts, opinion leaders, decision makers, and activists, may turn on shared norms, mores, values, preferences, decisions, and actions. Then there are powerful interest groups, which may be as mainstream as industry associations, or more fringe, including activists such as Greenpeace, PETA, etc., that promote specific agendas. The collective thoughts, feelings, and behaviors of such collectivities determine their impact. These powerful individuals and powerful groups make sense of context by way of what Kutz \& Bamford-Wade (2013) called contextual intelligence, an essential leadership competency, to which we now turn.

\section{The Importance of Contextual Intelligence}

First, what is contextual intelligence? For Kutz (2008: p. 23), contextual intelligence is "the ability to quickly and intuitively recognize and diagnose the dynamic contextual variables inherent in an event or circumstance and results in intentional adjustment of behaviour in order to exert appropriate influence in that context". The temporal dimension is important to note, in that contextual intelligence entails "an intuitive grasp of relevant past events, acute awareness of present contextual variables, and awareness of the preferred future" (Kutz, 2008: p. 18).

Khanna (2014: p. 60) described contextual intelligence quite simply as "the ability to understand the limits of our knowledge and to adapt that knowledge to an environment different from the one in which it was developed". That is, contextual intelligence enables one to intelligently apply and adapt relevant knowledge generated in one situation to a different one after giving due consideration to the limits of the former when applied to the latter. For Sternberg (1985: p. 45), it is the facility that "deals with the mental activity involved in attaining fit to context" i.e. the practical ability to adapt to contextual changes smartly.

In sum, contextually intelligent leaders are people who are able to interpret 
contextual information appropriately, assess contexts accurately, adapt their knowledge to particular contexts, and then choose appropriate actions, given what is known about past events, current demands, and projected future states. From the literature, one may propose that there are four important dimensions to contextual intelligence, namely: contextual sense-making; situation awareness and situation assessment; contextual adaptation; and response judgment.

Having described contextual intelligence, the next question is what the dimensions of contextual intelligence may look like. The first dimension is contextual sense-making, i.e. how to make sense or understand the prevailing situation. Cramer et al., (2006: p. 393) saw it as "a continuous process oriented towards placing current experiences (cues) in a frame of reference" based on past experiences. Alternatively, Daft and Weick (1984) defined sense-making as the process of scanning, interpreting, and action. By scanning is meant observing the surroundings to collect data and gather information to identify matters worthy of attention. By interpreting is meant that the data and information gathered get organized in such a way as to provide meaning and develop models to help determine what actions would henceforth be appropriate. Mental models are developed as representations to organize information, attribute meaning, and guide decision making.

The second dimension of contextual intelligence is situation awareness and situation judgment. Considering situation awareness first, it is the individual's "perception of the elements of the environment within a volume of time and space, the comprehension of their meaning and the projection of their status in the near future" (Endsley, 1995a: p. 65). Thus, it is that which leads to the development of a meaningful mental model of the current contextual state and possible future states. To have situation awareness would involve the leader perceiving environmental changes, interpreting relevant information pertaining to those changes, and, predicting likely future states based on those changes (Endsley, 1995b).

Situation awareness is related to contextual sense-making, which can be retrospective, or prospective (Gioia \& Mehra, 1996). Retrospective sensemaking seeks to make sense of past events while prospective sensemaking is about projecting how meaningful and desirable future states might look like. Tentative as it has to be, prospective sense-making which involves the projecting of future possibilities, comes into play especially when leaders are confronted with ambiguous situations. In such situations, prospective sense-making involves leaders modulating their existing knowledge structures and/or creating new ones on which they can hang meanings to these new situations and envision future desirable states (Gioia \& Mehra, 1996).

In challenging situations that are complex and ambiguous, situation awareness involves dynamic social processes. That is, while their prior experience and knowledge structures modulate their individual situation awareness, leaders also engage in collective sense-making. When people meet and share information to collaboratively develop a consensual awareness of the situation they are facing, they 
are likely to engage in both retrospective and prospective collective sense-making, (Weick, Sutcliffe, \& Obstfeld, 2005).

When people interact repeatedly over time as they try to come to grips with an emergent and ambiguous situation, they tend to come to influence one another's understandings and normative beliefs. Interlocutors who engage and interact regularly with one another, eventually form shared beliefs about the causation of challenges they face and shared rationales about what actions may be optimal to take. That is, they come to have shared mental models, or collectively-held knowledge structures which enable them to frame problems, explain situations of interest, and predict future states. In sum, to facilitate this collective or organizational sense-making-to build shared, context-specific mental models for situation assessment-it is necessary for leaders to be immersed in different social contexts, interact with the relevant key stakeholders, and develop the necessary social networks.

Now to consider situation judgment. This involves the leader trying to grasp what may be significant in a particular situation, making attributions as to causes and consequences, and predicting future states. For Rockstuhl et al., (2015: p. 465), it is the "sense-making of a situation, which enables [individuals] to comprehend, explain, attribute, extrapolate, and predict situations". Thus, it is the process of sizing up one's understanding of a particular situation and then contextualizing its relevance and significance. It is a nuanced process during which the leader transits from gaining an understanding about a situation, i.e. having situation awareness, to making a situation judgment, or assessing the current and future significance of a particular situation.

There is a process of moving from sense-making to sense-giving. In sense-giving, leaders enable others, such as subordinates and followers, to understand their assessment of a particular situation. Within an organization, sense-giving involves leaders convincing others of their situation judgments (Gioia \& Chittipeddi, 1991; Rouleau, 2005). Take the case where an investment bank's top management develops the situation awareness of the importance of AI and ML in banking. These leaders then proceed to situation judgment, judging that AI and ML will be dispositive to sustaining bank financial performance because AI and ML present not only opportunities for creating innovative investment services but also multiple avenues for cost cutting. That close competitors have already invested heavily in AI and ML may help them convince others of an urgency in investing in AI and ML.

The third dimension of contextual intelligence is contextual adaptation, i.e. adapting as one's situation awareness and situation judgment. Leaders have "to adjust their thoughts and behaviors to enact appropriate responses to novel, ill-defined, changing, and evolving decision-making situations" (Hannah et al., 2013: p. 393), so as to achieve a degree of fit between their actions and the demands of the external environment (Chan, 2000). This entails adapting one's knowledge, attitudes, and behaviours to perform appropriately in a given context, being mindful of multi-cultural and cross-cultural sensitivities (Filho, Au- 
bertin, \& Petiot, 2016).

The fourth dimension of contextual intelligence is response judgment, i.e. judging as to what response best meets the requirements of a particular situation. This is the deciding of what a suitable course of action might be (Jansen et al., 2013). It involves choosing between alternative courses of actions based on their respective consequences. This might take the form of adaptive decision-making, such as solving problems creatively when dealing with evolving or unforeseen situations or crisis situations (Pulakos et al., 2000, 2002). The primary concern at this juncture is to choose strategic options that will empower people in an organization to respond effectively to the external demands of an environmental change.

Now, these four dimensions may be profitably put together for a model of contextual intelligence. Based on the above discussion of the literature on contextual intelligence, the four dimensions of contextual intelligence can be seen as working in concert with one another in what may be called the diamond model of contextual intelligence (Figure 2).

Because contextualized knowledge is needed for building situation awareness which impacts situation judgment, adaptation, and response of organizational leaders, the key in this model is contextual sense-making. More granular detail is added to Figure 2 by including the relevant contextual levels for each dimension of the model, whilst also emphasizing that leaders will need to navigate among the various contextual levels (Figure 3 ).

To put some flesh on this framework in Figure 3, imagine a group of leaders from different investment banks who have been considering the technology landscape (macro environment level), looking specifically at artificial intelligence (AI) and machines learning (ML). In associational meetings, they discuss the impact of AI\&ML on the banking industry (aggregate environment level).

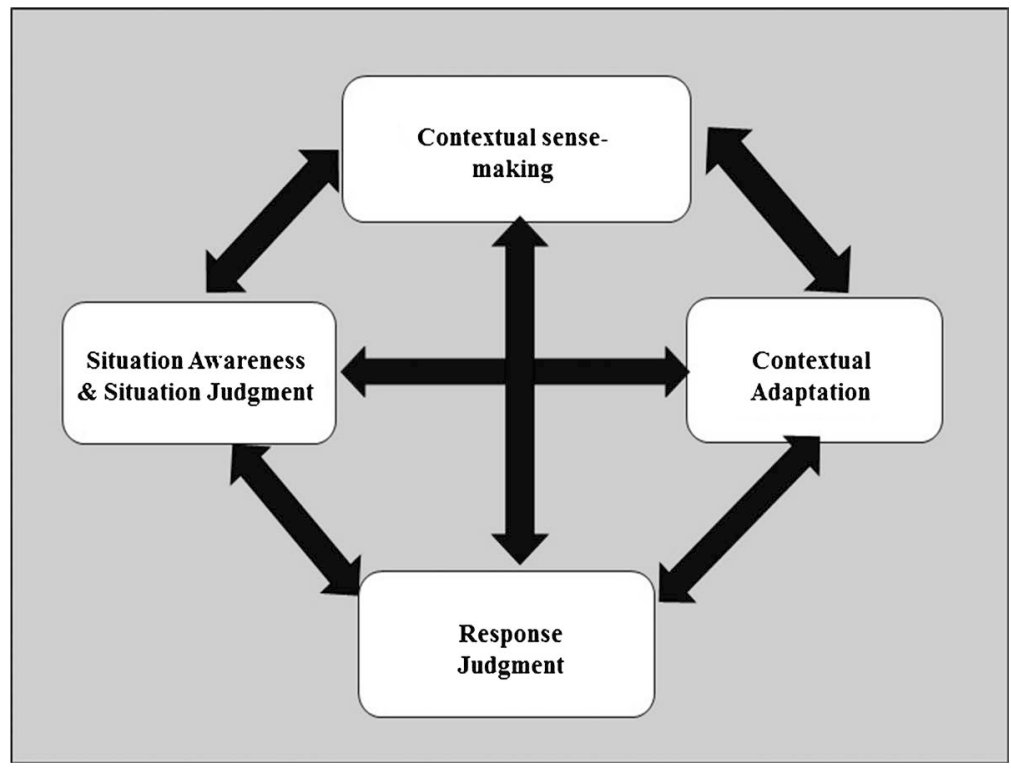

Figure 2. The diamond model of contextual intelligence. 


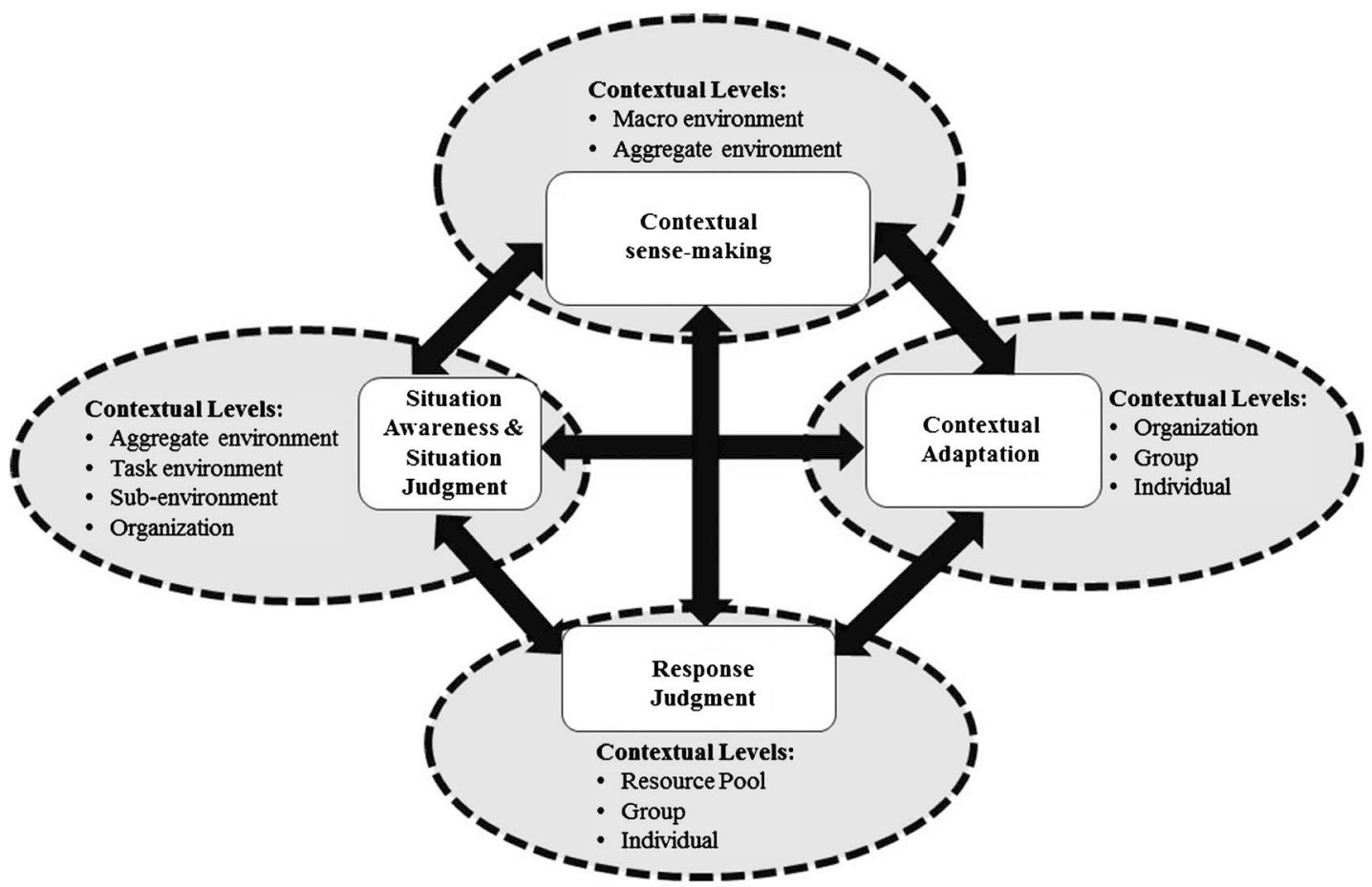

Figure 3. The diamond model of contextual intelligence in greater detail.

From these and other social interactions with one another, they develop a shared situation awareness about AI\&ML in banking. In trying to think through what these technologies may imply for their relative competitiveness (task environment level), some of them might perceive these technologies as threats to overcome, while others may regard them as presenting opportunities (sub-environment level).

With their heightened situation awareness about AI\&ML, these bankers make situation judgments. They will make a judgment call as to whether they will put on the back burner any decision on them, or if they will invest in these technologies (organization level). Assuming they adjudge AI\&ML as poised to play very significant roles in banking, they will next consider the kind of contextual adaptations needed to incorporate them in their operations at organization, group, and individual levels.

Contextual adaptations may vary by contextual levels because of different contextual factors. For example, at the organization level, top management may consider how to reallocate its resources to invest in AI\&ML. At group level, different departments, divisions, or workgroups may have to reengineer their business processes to incorporate AI\&ML. At the individual level, contextual adaptations may mean workers have to be sent for training in AI \& ML to develop new capabilities. Once the necessary adaptations are put in place, the leadership can determine more specifically the responses needed to best meet the challenges that $\mathrm{AI} \& \mathrm{ML}$ pose.

All this is not to imply that contextualizing will lead inexorably to perfect plans for the future since leaders can never predict the future perfectly (Quinn, 1980). Also, the decision context can be messy with streams of complex, uncer- 
tain, and ambiguous problems, solutions, participants and choice opportunities (Cohen, March, \& Olsen, 1972). Simply put, problems do not present themselves as something unambiguously understandable. Instead, leaders must understand them, and articulate their situational judgments, which will inform what contextual adaptations are necessary and what responses are to be made. In judging what responses are appropriate, leaders will choose among the various options of linking problems to opportunities, solutions, participants and decisions. To do this well, leaders must have the requisite complexity themselves, to which we now turn.

\section{Requisite Complexity for Developing Contextual Intelligence}

When leaders interact with different groups of people at different levels, they are essentially navigating the different contextual levels described up to this point. To be able to do so effectively in a VUCA world, leaders must be able to develop a deeper understanding of problems, recognize changing contexts, and come up with the appropriate adaptations (Bell \& Kozlowski, 2008). Such leaders recognize not just how complex human interactions may be but are also contextually-sensitized. Since leadership is a process involving different sets of people in different contexts and situations, a process that works is that which encourages inclusiveness, values individual differences, and promotes collaborative learning and innovative adaptation. To function well in such a process requires leaders themselves to have the requisite complexity that enables them to be highly adaptive, so that they can quickly modify their responses to and play different roles in different contexts (Hannah et al., 2013). In sum, leaders must match their complexity to the complexity in the environment.

Lord, Hannah, and Jennings (2011) argued that the requisite complexity comprises the following domains, viz., general cognitive complexity; social complexity; self-complexity; and, affective complexity. First, cognitive complexity is the "ability to differentiate and integrate abstract information in a particular domain" (Lord et al., 2011: p. 106). It is the cognitive capacity to process abstract informational stimuli through either differentiation or integration, or both. The former involves dissecting information into smaller elements while the latter involves blending informational elements into a coherent whole. Leaders who can do both tend to understand abstract information more accurately and synthesize that information more coherently (Bartunek et al., 1983). In this way, cognitively complex leaders develop collective sense-making, situation awareness and situation judgment that are more accurate.

Second, social complexity is the "ability to perceive and integrate multiple aspects of social roles relations" (Lord et al., 2011: p. 106). It impacts the ability of individuals to function appropriately vis-à-vis the varying social demands of different contexts. The variety of social situations is largely a function of the diversity of stakeholders that leaders must interact with in differing capacities or roles.

Social complexity manifests in the range of social behaviors of leaders as they interact with diverse sets of followers, heterogeneous teams, and external stake- 
holders (Zaccaro, 2001). Socially complex leaders are more able to navigate different contextual levels, e.g. from external stakeholders to teams at lower levels in an organization. For such leaders, the appropriate personality traits are evoked, appropriate leadership styles enacted, and the right sensitivity to multicultural contexts manifested (Zaccaro, Green, Dubrow, \& Kolze, 2018).

Third, self-complexity has to do with how one's self-concept influences how one processes information and regulates oneself (Kihlstrom \& Klein, 1994; Verplanken \& Holland, 2002). In this connection, self-complexity may be thought of as one's self-regulatory and metacognitive structures for "managing the interface between a leader's intrapersonal processes and the higher level interpersonal behaviors associated with leading" (Lord, Hannah, \& Jennings, 2011: p. 106). Metacognition is higher-order thinking in the sense of cognizing one's own cognizing or being aware of one's awareness, which facilitates learning and enables adaptive transfer to real life situations (Ivancic \& Hesketh, 2000). It is one's inventory of knowledge, skills and abilities driving leader agility that they can draw upon to adapt to changing contexts (Lord et al., 2011). Self-complexity facilitates and colors how one constructs meanings and develops a repertoire of thoughts and behaviors (Lord et al., 2011).

Finally, affective complexity is the capacity "to understand and respond to both positive and negative events and [to] positive and negative emotions in others" (Lord et al., 2011: p. 106). For obvious reasons, leaders who are high in affective complexity are those who can process both positive and negative affective inputs, to generate adaptive responses.

For leaders to become effective ones who can evince contextually intelligent leadership, they will need to develop the requisite complexity to address VUCA problems (Figure 4). In the framework which Lord, Hannah, and Jennings (2011) proposed that links the requisite complexity to adaptability, leaders must attend to the various levels of contexts, cognitively and behaviorally, if they are to adjust effectively as contexts change. Only leaders with the requisite complexity can manifest the behavioral complexity to create adaptive systems to do so

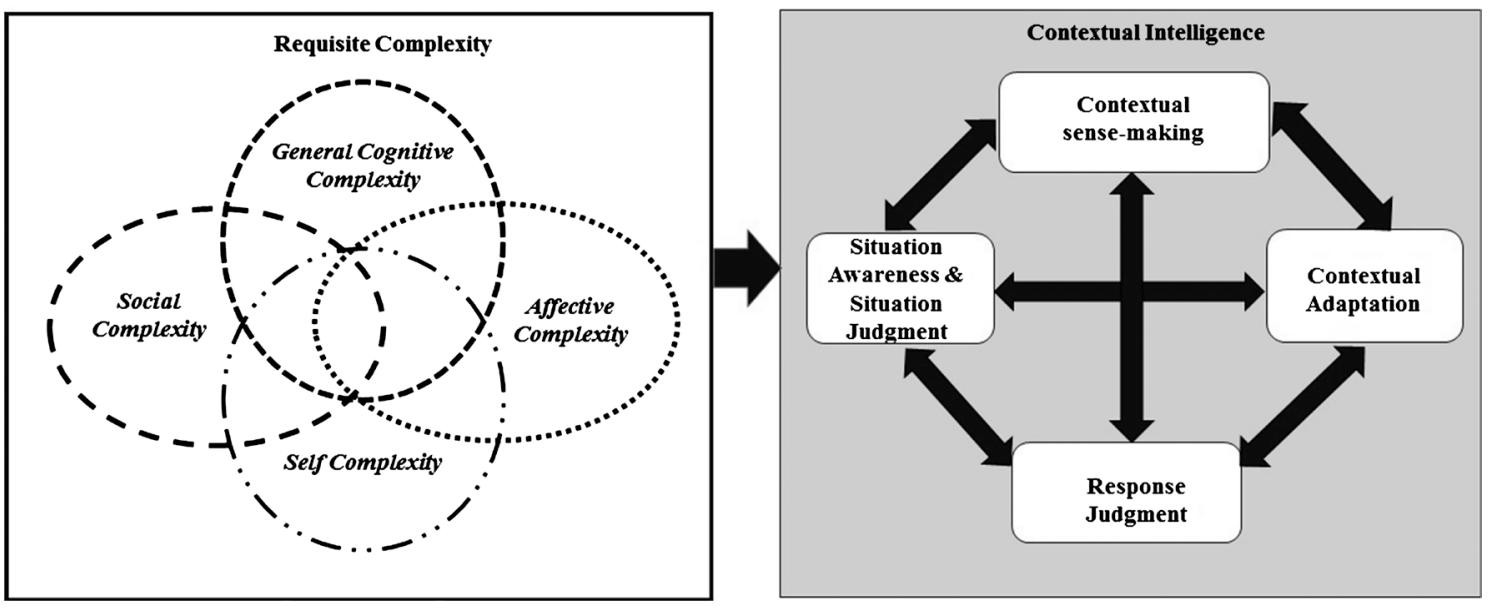

Figure 4. Model of contextual leadership development. 
(Hooijberg, Hunt, \& Dodge, 1997).

The hope is for leaders to dynamically integrate all four domains of the requisite complexity to meet the complex demands of different contexts. For example, in deliberating about the potential of AI\&ML for their business, leaders collectively develop contextual sense-making on AI\&ML (facilitated by their general cognitive complexity). In implementing related initiatives, leaders will need to persuade departmental managers of their situation judgment regarding AI\&ML (facilitated by their social complexity). In making contextual adaptations, leaders will need to adapt their goals and values according to the emerging work contexts that are enabled by AI\&ML and be sensitive to their own emotions and those of others who are impacted by their response judgment (facilitated by their self and affective complexities). In sum, contextual intelligent leaders should be able to dynamically draw upon and integrate all four domains as they navigate across different contextual settings. Now, what remains is how the requisite complexity in individuals may be fostered so they can become contextually intelligent leaders. To this question, we turn next.

\section{A Pedagogical Framework for Developing Contextual-Intelligent Leadership}

Purpose-designed instructional programs are needed to develop leaders with the requisite complexity to deal with VUCA challenges in contextually-intelligent ways (Figure 5).

The first design component of an instructional program to develop leaders with the requisite complexity so they can be contextually intelligent is a focus on learning outcomes. These should be explicitly stated so that learners know precisely

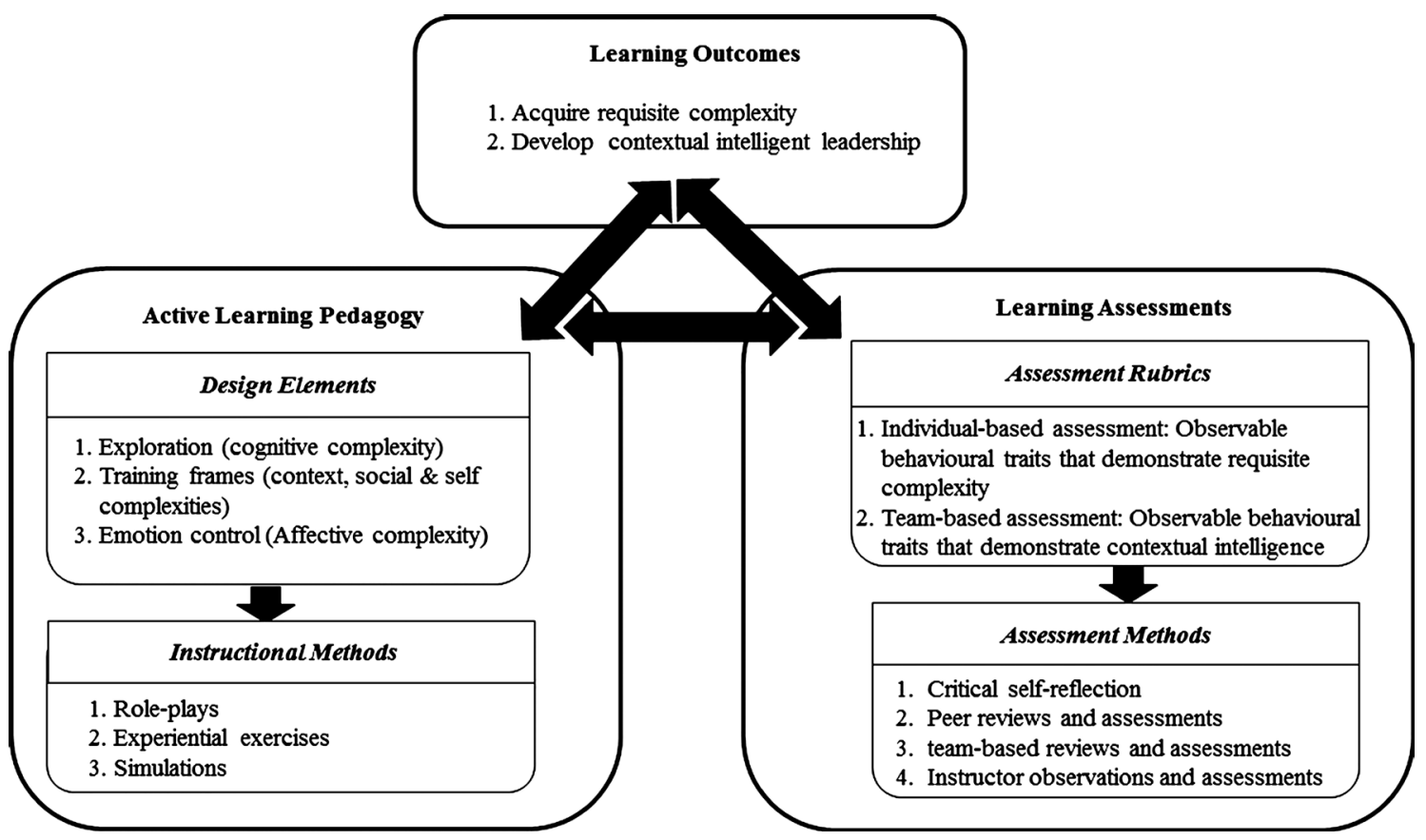

Figure 5. Pedagogical framework for developing contextual intelligent leadership. 
what knowledge, skills, and abilities they will acquire after they have gone through a particular training program. In the present context, there are two important learning outcomes that need no farther discussion, viz., the acquisition of requisite complexity, and the development of contextual intelligence.

The second component of said instructional program would be formal learning assessments. Feedback is critical to assessing how effective a program might be in regard to achieving its specified learning outcomes. For this purpose, assessment rubrics ought to be designed to assess learning effectiveness at both individual and team levels.

In designing assessment rubrics, observable traits and behaviors associated with the knowledge, skills, and abilities that learners are expected to demonstrate are first specified. This is then followed by describing how the various performance levels for each item in the rubric, whether exemplary, acceptable, or below-expectation, ought to look like. Table 1 lists the details in a sample rubric for assessing requisite complexity in individuals and contextual intelligence in teams.

Table 1. Assessment rubrics: Samples of observable behaviors.

A. Individual-based assessment: Requisite complexity rubric

1. General cognitive complexity

- Apply diverse perspectives

- Synthesize multiple perspectives

2. Social complexity

- Show sensitivity to the needs of others

- Use the appropriate leadership style to influence others

3. Self-complexity

- Identify multiple attributes of self

- Associate with a wide range of roles

4. Affective complexity

- Create positive situations to enhance positive affect

- Transform negative situations to reduce stress

B. Team-based assessment: Contextual intelligent leadership rubric

1. Contextual sense-making

- Seek information from diverse contexts

- Network with diverse sets of stakeholders

2. Situation awareness and judgment

- Grasp the significance of a situation to generate situation awareness

- Provide evidenced-based justifications to support leaders' situational judgment

- Apply appropriate means to convince others to get on the bandwagon

3. Contextual adaptation

- Create adaptive systems and procedures

- Manifest adaptive attitudes and behaviors

- Encourage change and promote creativity and innovation

4. Response judgment

- Generate alternative courses of action

- Show adaptive decision making

- Consider unintended consequences of decisions 
There is a diversity of methods to assess learning for the individual and teams. First, through critical self-reflection, learners may gain deeper insights about their own cognitive processing, self-attribution, social acumen, and emotion control. Second, peer review and assessment can encourage learners to share their thoughts and opinions with one another. Third, mutual sharing and exchange of assessments can offer learners ample opportunity to check if their self-reflections are valid.

The final component of an instructional program to develop leaders with the requisite complexity to be contextually intelligent would be pedagogies that promote active learning. Active learning encourages active participation by learners, who are held responsible for their own learning. Learners are provided ample opportunities to explore, experiment, reflect, and then infer the strategies and actions for effective performance.

In active learning, pedagogical techniques such as experiential learning, simulations, or role-plays enable the arousal of emotions in a setting that is psychologically safe (Bowen, 1987; Tompson \& Dass, 2000). In role plays, for example, learners are likely to experience stress and anxiety (Keith \& Frese, 2005) just as leaders face in a VUCA environment. Thus, designing active learning pedagogies that deal with the resolving of stressful and anxious situations in a workplace scenario would be good labs for participants to acquire the skill of emotion control while improving their own knowledge (Shaw \& Switky, 2018).

According to Bell and Kozlowski (2008), interventions that promote active learning effectively tend to stress exploration, training frame, and emotion control. A guided exploratory instructional design is to be preferred as structured discovery ensures learning more effectively than unstructured discovery (Mayer, 2004). Moreover, guided exploration promotes metacognition (Ivancic \& Hesketh, 2000). Then, there is the matter of training frames, which can prime learners for specific learning outcomes. For example, an error frame is one that posits making mistakes as being important to learning, while a practice frame is one that promotes the idea of practice as learning opportunity (Frese et al., 1991). In this sense, a contextual frame might be one that posits context as meaning-making. Such a frame would conduce learners to manifest sensitivity to others, be alert to their own self-aspects, be mindful of the bigger picture, and develop self- and social-complexities.

A pedagogically effective role play would attend to the core design elements advanced by Bell and Kozlowski (2008). Role plays that put the spot light on the affective state of the role players will help them cultivate higher affective complexity. Such role-plays can be effective in creating longer lasting memories, thus instilling retainable leadership skills (Hertel \& Millis, 2002; Monahan, 2002). Role play vignettes also serve as microcosms of leadership settings if they provide pertinent information on contextual influences. Relevant contextual elements have to be specifically written into one's role play scripts, which should be rich in communication and experiential interaction. Learners may be given fully scripted, partially scripted, or completely unscripted roles. They may need to be 
told to refer specifically to various contextual aspects in their role-playing. Learners may take on different roles in these scenarios that either simulate real life or may be fictitious ones created by the instructor. Instructors may create different role play scenarios to simulate different contextual levels and leadership situations. Purposefully constructed role plays can set a foundation for behavioral shifts.

In playing their roles, learners may take on different personae, which can either be fictional characters or composites based on real people (Little, 1990). For scripts to provide realistic, interactive role-plays, they have to be written to reflect real life leadership challenges. Learners, like stage actors and actresses, must try to realistically embody the motives, values, and behaviors of the hypothetical sets of people. Role players may take on specific affective states specified by the instructor or manifest their own natural affective states, depending on the design of the role play, so as to reflect real-life situations comprehensively.

Finally, meaningful de-briefs must be held to distil leadership insights from each role play. A congenial learning environment must be created beforehand to encourage openness in sharing one another's vulnerabilities, weaknesses, or errors. Then, debriefing is done at the end of each role play, when experiences are still fresh in the minds of learners. This should focus on the recall of role play experiences to see what was helpful and what was not, analyze the extent to which the various learning outcomes were accomplished, and suggest ways for future improvement.

\section{Conclusion}

To perform well in today's VUCA environment, organizational leadership must get out of the leadership gap trap identified by the Center of Creative Leadership. Contextually intelligent leadership will be able to do just that in discerning dynamic trends in the environment, make sense of their implications, anticipate the responses of strategic stakeholders, and respond adaptively. This paper proposed a contextual intelligence model and advanced a leadership development model that underscores the requisite complexity leaders must acquire to grow and fine tune their contextual intelligence. The conceptual underpinnings of a framework to design active learning pedagogies to foster the requisite complexity for developing contextual intelligence were also described. Instructors may use this framework as a guide in designing innovative learning methods to equip leaders with contextually intelligent adaptive complexities to meet VUCA challenges. This model of contextual intelligence may also be profitably used for training in other areas such as conflict management, change management, and scenario planning.

\section{Conflicts of Interest}

The author declares no conflicts of interest regarding the publication of this paper. 


\section{References}

Bartunek, J. M., Gordon, J. R., \& Weathersby, R. P. (1983). Developing “Complicated” Understanding in Administrator. Academy of Management Review, 8, 273-284.

Bass, B. M., \& Avolio, B. J. (1990). Developing Transformational Leadership: 1992 and Beyond. Journal of European Industrial Training, 14, 21-27. https://doi.org/10.1108/03090599010135122

Bell, B. S., \& Kozlowski, S. W. J. (2008). Active Learning: Effects of Core Training Design Elements on self-Regulatory Processes, Learning, and Adaptability. Journal of Applied Psychology, 93, 296-316. https://doi.org/10.1037/0021-9010.93.2.296

Blake, R., \& Mouton, J. (1985). The Managerial Grid III. Houston, TX: Gulf.

Blanchard, K., Zigarmi, P., \& Nelson, R. (1993). Situational Leadership ${ }^{\circledast}$ after 25 Years: A Retrospective. Journal of Leadership Studies, 1, 22-36. https://doi.org/10.1177/107179199300100104

Boal, K. B. (2000). Strategic Leadership Research: Moving On. Leadership Quarterly, 11, 515-549. https://doi.org/10.1016/S1048-9843(00)00057-6

Bowen, D. D. (1987). Developing a Personal Theory of Experiential Learning: A Dispatch from the Trenches. Simulation \& Games, 18, 192-206. https://doi.org/10.1177/104687818701800203

Cappelli, P., \& Sherer, P. D. (1991). The Missing Role of Context in OB: The Need for a Meso-Level Approach. Research in Organizational Behavior, 13, 55-110.

Castrogiovanni, G. J. (1991). Environmental Munificence: A Theoretical Assessment. Academy of Management Review, 16, 542-565. https://doi.org/10.2307/258917

Chakravorty, U., Hubert, M.-H., \& Marchand, B. U. (2018). Food for Fuel: The Effect of the US Biofuel Mandate on Poverty in India. Discussion Paper Series No. 11784, Bonn: IZA Institute.

Chan, D. (2000). Understanding Adaptation to Changes in the Work Environment: Integrating Individual Difference and Learning Perspectives. Research in Personnel and Human Resources Management, 18, 1-42.

Ciampa, D. (2005). Almost Ready: How Leaders Move Up. Harvard Business Review, 83, 46-53.

Cohen, M. D., March, J. G., \& Olsen, J. P. (1972). A Garbage Can Model of Organizational Choice. Administrative Science Quarterly, 17, 1-25. https://doi.org/10.2307/2392088

Cramer, J., Van Der Heijden, A. and Jonker, J. (2006). Corporate Social Responsibility: Making Sense through Thinking and Acting. Business Ethics: A European Review, 15, 380-389. https://doi.org/10.1111/j.1467-8608.2006.00459.x

Daft, R. L., \& Weick, K. E. (1984). Toward a Model of Organizations as Interpretation Systems. The Academy of Management Review, 9, 284-295. https://doi.org/10.5465/amr.1984.4277657

Endsley, M. R. (1995a). Measurement of Situation Awareness in Dynamic Systems. Human Factors, 37, 65-84. https://doi.org/10.1518/001872095779049499

Endsley, M. R. (1995b). Toward a Theory of Situation Awareness in Dynamic Systems. Human Factors, 37, 32-64. https://doi.org/10.1518/001872095779049543

Fiedler, F. (1964). A Contingency Model of Leadership Effectiveness. In L. Berkowitz (Ed.), Advances in Experimental Social Psychology (Vol. 1, pp. 149-190). New York: Academic Press. https://doi.org/10.1016/S0065-2601(08)60051-9

Filho, E., Aubertin, P., \& Petiot, B. (2016). The Making of Expert Performers at Cirque du Soleil and the National Circus School: A Performance Enhancement Outlook. Journal 
of Sport Psychology in Action, 7, 68-79. https://doi.org/10.1080/21520704.2016.1138266

Frese, M., Brodbeck, F., Heinbokel, T., Mooser, C., Schleiffenbaum, E., \& Thiemann, P. (1991). Errors in Training Computer Skills: On the Positive Function of Errors. Human-Computer Interaction, 6, 77-93. https://doi.org/10.1207/s15327051hci0601_3

Geist, D. B., \& Myers, M. E. (2007). Pedagogy and Project Management: Should You Practice What You Preach? Journal of Computer Science in Colleges, 23, 202-208.

Gioia, D. A., \& Mehra, A. (1996). Sense-Making in Organizations. Academy of Management Review, 21, 1226-1230. https://doi.org/10.2307/259169

Gioia, D., \& Chittipeddi, K. (1991). Sense-Making and Sense-Giving in Strategic Change Initiation. Strategic Management Journal, 12, 433-448. https://doi.org/10.1002/smj.4250120604

Graen, G., \& Uhl-Bien, M. (1995). Relationship-Based Approach to Leadership: Development of Leader-Member Exchange (LMX) Theory of Leadership over 25 Years. Leadership Quarterly, 6, 219-247. https://doi.org/10.1016/1048-9843(95)90036-5

Gronn, P. (2002). Distributed Leadership as a Unit of Analysis. The Leadership Quarterly, 13, 423-451. https://doi.org/10.1016/S1048-9843(02)00120-0

Hannah, S. T., Balthazard, P. A., Waldman, D. A., Jennings, P. L., \& Thatcher, R. W. (2013). The Psychological and Neurological Bases of Leader Self-Complexity and Effects on Adaptive Decision-Making. Journal of Applied Psychology, 98, 393-411. https://doi.org/10.1037/a0032257

Hannah, S. T., Cambbell, D. J., \& Matthews, M. D. (2010). Advancing a Research Agenda for Leadership in Dangerous Contexts. Military Psychology, 22, S157-S189. https://doi.org/10.1080/08995601003644452

Hertel, J. P., \& Millis, B. J. (2002). Using Simulation to Promote Learning in Higher Education. Sterling: Stylus.

Hooijberg, R., Hunt, J. G., \& Dodge, G. E. (1997). Leadership Complexity and Development of the Leaderplex Model. Journal of Management, 23, 375-408. https://doi.org/10.1177/014920639702300305

Ivancic, K., \& Hesketh, B. (2000). Learning from Error in a Driving Simulation: Effects on Driving Skill and Self-Confidence. Ergonomics, 43, 1966-1984.

https://doi.org/10.1080/00140130050201427

Jansen, A., Melchers, K. G., Lievens, F., Kleinmann, M., Brändli, M., Fraefel, L., \& König, C. J. (2013). Situation Assessment as an Ignored Factor in the Behavioral Consistency Paradigm Underlying the Validity of Personnel Selection Procedures. Journal of Applied Psychology, 98, 326-341. https://doi.org/10.1037/a0031257

Johns, G. (2006). The Essential Impact of Context on Organizational Behavior. Academy of Management Review, 31, 386-408. https://doi.org/10.5465/amr.2006.20208687

Keith, N., \& Frese, M. (2005). Self-Regulation in Error Management Training: Emotion Control and Metacognition as Mediators of Performance Effects. Journal of Applied Psychology, 90, 677-691. https://doi.org/10.1037/0021-9010.90.4.677

Khanna, T. (2014). Contextual Intelligence. Harvard Business Review, 92, 59-68.

Kihlstrom, J. F., \& Klein, S. B. (1994). The Self as a Knowledge Structure. In R. S. Wyer, \& T. K. Srull (Eds.), Handbook of Social Cognition. Vol. 1: Basic Processes (pp. 153-208). Hillsdale, NJ: Erlbaum.

Kutz, M. R. (2008). Toward a Conceptual Model of Contextual Intelligence: A Transferable Leadership Construct. Leadership Review, 8, 18-31.

Kutz, M. R., \& Bamford-Wade, A. (2013). Understanding Contextual Intelligence: A 
Critical Competency for Today's Leaders. E: CO Issue, 15, 55-80.

Leslie, J. B. (2015). The Leadership Gap. Center for Creative Leadership.

Little, L. (1990). Beyond Role-Play: Character Immersion in the Organizational Behavior Class. Journal of Management Education, 14, 46-53. https://doi.org/10.1177/105256298901400406

Lord, R. G., Hannah, S. T., \& Jennings, P. L. (2011). A Framework for Understanding Leadership and Individual Requisite Complexity. Organizational Psychology Review, 1, 104-127. https://doi.org/10.1177/2041386610384757

Mayer, R. E. (2004). Should There Be a Three-Strikes Rule against Pure Discovery Learning? The Case for Guided Methods of Instruction. American Psychologist, 59, 14-19. https://doi.org/10.1037/0003-066X.59.1.14

Monahan, G. (2002). Acting out Nazi Germany: A Role-Play Simulation for the History Classroom. Teaching History: A Journal of Methods, 27, 74-86.

Mowday, R. T., \& Sutton, R. I. (1993). Organizational Behavior: Linking Individuals and Groups to Organizational Contexts. Annual Review of Psychology, 44, 195-229. https://doi.org/10.1146/annurev.ps.44.020193.001211

Mumford, M., Zaccaro, S., Connelly, M., \& Marks, M. (2000). Leadership Skills: Conclusions and Future Directions. Leadership Quarterly, 11, 11-35. https://doi.org/10.1016/S1048-9843(99)00041-7

Plowman, D. A., \& Duchon, D. (2008). Dispelling the Myths about Leadership: From Cybernetics to Emergence. In M. Uhl-Bien, \& R. Marion (Eds.), Complexity Leadership Part 1: Conceptual Foundations (pp. 129-153). Charlotte, NC: Information Age Publishing.

Pulakos, E. D., Arad, S., Donovan, M. A., \& Plamondon, K. E. (2000). Adaptability in the Workplace: Development of a Taxonomy of Adaptive Performance. Journal of Applied Psychology, 85, 612-624. https://doi.org/10.1037/0021-9010.85.4.612

Pulakos, E. D., Schmitt, N., Dorsey, D. W., Arad, S., Hedge, J. W., \& Borman, W. C. (2002). Predicting Adaptive Performance: Further Tests of a Model of Adaptability. Human Performance, 15, 299-324. https://doi.org/10.1207/S15327043HUP1504_01

Quinn, J. B. (1980). Strategies for Change: Logical Incrementalism. Homewood, IL: Richard E. Irwin, Inc.

Rockstuhl, T., Ang, S., Ng, K. Y., Lievens, F., \& Van Dyne, L. (2015). Putting Judging Situations into Situational Judgment Tests: Evidence from Intercultural Multimedia SJTs. Journal of Applied Psychology, 100, 464-480. https://doi.org/10.1037/a0038098

Rouleau, L. (2005). Micro-Practices of Strategic Sense-Making and Sense-Giving: How Middle Managers Interpret and Sell Change Every Day. Journal of Management Studies, 42, 1413-1441. https://doi.org/10.1111/j.1467-6486.2005.00549.x

Rousseau, D. M., \& Fried, Y. (2001). Location, Location, Location: Contextualizing Organizational Research. Journal of Organizational Behavior, 22, 1-13. https://doi.org/10.1002/job.78

Shaw, C. M., \& Switky, B. (2018). Designing and Using Simulations in the International Relations Classroom. Journal of Political Science Education, 14, 523-534. https://doi.org/10.1080/15512169.2018.1433543

Sternberg, R. J. (1985). Beyond IQ: A Triarchic Theory of Intelligence. Cambridge: Cambridge University Press.

Tetenbaum, T., \& Laurence, H. (2011). Leading in the Chaos of the 21st Century. Journal of Leadership Studies, 4, 41-44. https://doi.org/10.1002/jls.20191

Tompson, G. H., \& Dass, P. (2000). Improving Students' Self-Efficacy in Strategic Man- 
agement: The Relative Impact of Cases and Simulations. Simulation \& Gaming, 31, 22-41. https://doi.org/10.1177/104687810003100102

Uhl-Bien, M., Marion, R., \& Mckelvey, B. (2008). Complexity Leadership Theory: Shifting Leadership from the Industrial Age to the Knowledge Era. In M. Uhl-Bien, \& R. Marion (Eds.), Complexity Leadership Part 1: Conceptual Foundations (pp. 185-224). Charlotte, NC: Information Age Publishing.

Verplanken, B., \& Holland, R. (2002). Motivated Decision Making: Effects of Activation and Self-Centrality of Values on Choices and Behavior. Journal of Personality and Social Psychology, 82, 434-447. https://doi.org/10.1037/0022-3514.82.3.434

Weberg, D. (2012). Complexity Leadership: A Healthcare Imperative. Nursing Forum, 47, 268-277. https://doi.org/10.1111/j.1744-6198.2012.00276.x

Weick, K. E., Sutcliffe, K. M., \& Obstfeld, D. (2005). Organizing and the Process of Sense-Making. Organization Science, 16, 409-421. https://doi.org/10.1287/orsc.1050.0133

World Economic Forum (2015). Outlook on the Global Agenda 2015. http://www3.weforum.org/docs/GAC14/WEF_GAC14_OutlookGlobalAgenda_Report. pdf

Zaccaro, S. J. (2001). The Nature of Executive Leadership: A Conceptual and Empirical Analysis of Success. Washington DC: American Psychological Association. https://doi.org/10.1037/10398-000

Zaccaro, S. J., Green, J. P., Dubrow, S., \& Kolze, M. J. (2018). Leader Individual Differences, Situational Parameters, and Leadership Outcomes: A Comprehensive Review and Integration. The Leadership Quarterly, 29, 2-43.

https://doi.org/10.1016/j.leaqua.2017.10.003

Zaccaro, S., Kemp, C., \& Bader, P. (2004). Leader Traits and Attributes. In J. Antonakis, A. T. Cianciolo, \& R. J. Sternberg (Eds.), The Nature of Leadership (pp. 101-124). Thousand Oaks, CA: Sage. 